\title{
Environmental Impact and Cost Evaluation in Remanufacturing Business Decision Support
}

\author{
Rossella Luglietti ${ }^{1}$, Federico Magalini ${ }^{1}$, Marco Taisch ${ }^{1}$, and Jacopo Cassina ${ }^{2}$ \\ ${ }^{1}$ Politecnico di Milano via Lambruschini 4b, 20156 Milano, Italy \\ \{rossella.luglietti, federico.magalini, marco.taisch\}@polimi.it \\ ${ }^{2}$ Holonix Corso Italia 8, 20821 Meda, Italy \\ jacopo.cassina@holonix.it
}

\begin{abstract}
The research implements a business decision support system to evaluate environmental and economic implications for different end of life alternatives strategies. The case study described in the paper is the evaluation of end of life automotive engine. In detail, the analysis consists of the evaluation of environmental impacts and economic costs of engine remanufacturing process. In particular, will be compared three different alternatives: remanufacturing, reuse and recycling (material recovery). Thanks to remanufacturing, it is possible anyway to increase end-of-life benefits, compared with recycling, avoiding, from a life cycle perspective, the manufacturing process of new products through refurbishing or reuse, preventing at the same time certain generation of waste. Results will be shown in a bi-dimensional graph displaying the three alternatives with their economic revenue and environmental gain.
\end{abstract}

Keywords: LCA, Remanufacturing, End of Life, Recycling, ICT.

\section{Introduction}

Waste is a key environmental and economic issue and a growing problem. The amount of waste generated in Europe continues to rise each year; approximately 3 billion tons of waste are thrown away in the European Union annually. This amounts to about 6 tons of solid waste for every European [1].

On this scenario, waste management is going more and more an important part of European business. Good practices will increase the benefits from waste collection. In fact, the improvement of separated collection will increment the secondary raw materials sold, and the benefit in terms of profits and environmental gain.

The connection between economic growth and environmental impacts associated with waste generation is a key objective of the EU's revised Waste Framework Directive (Directive2008/98/EC). The policy of European Commission is to reverse the waste growth. The European legislation introduced the waste hierarchy within the EU's Sixth Environmental Action Programme [2], developing the waste overturned pyramid, which identifies waste management priorities. The pyramid base represents the best option, identified by prevention, and the vertex expresses the worst choice in terms of environmental gain [3]. The European Commission promotes waste recovery

B. Grabot et al. (Eds.): APMS 2014, Part II, IFIP AICT 439, pp. 415-422 2014.

(C) IFIP International Federation for Information Processing 2014 
as key strategy to reduce the quantity of waste for disposal and saving natural resources, in particular by reuse, recycling, composting and recovering energy from waste. From the European perspective, remanufacturing includes the activities to prepare for reuse of products.

It was recognized that the identification and selection of the best end-of-life options should regard to environmental and economic effects, taking into account scientific and technological progress and life cycle analyses to be further developed. Reuse and material recovery should be considered preferable where and in so far as, they are the best environmental options [4].

Remanufacturing is a standardized industrial process of bringing used products, worn or non-functional, to "like-new" functional state with equivalent condition and function than the new original one. Remanufactured parts have the same as the warranty required for new products equivalent. Remanufacturing is going to be a common practice, especially for complex products with high value to implement the waste prevention. At the moment, the major sectors where remanufacturing is developed are: automotive, ICT equipment, ink and toner, medical, precision and optical equipment, pumps and compressors and tires [5].

The research presented is being developed in the context of the PREMANUS project, a co-funded project by the European Union under the ICT theme of the 7th framework program for R\&D. Part of the project is focusing on development of a business decision support system to take the best selection, considering both the economic aspects and environmental implications, for different end of life alternatives of complex products. In detail, this research is focused on remanufacturing of automotive light engine, one of the three case applications developed under the PREMANUS project.

The eco-efficiency diagram is introduced (Fig. 1), allowing the interaction between economic and environmental dimensions into the decision making process. On the Yaxis of the diagram it can plot an economic indicator (in this case $€$ ) for the total costs occurring during the remanufacturing process. The $\mathrm{X}$-axis represents the environmental indicator (it has been chosen the equivalent $\mathrm{CO}_{2}$ emission).

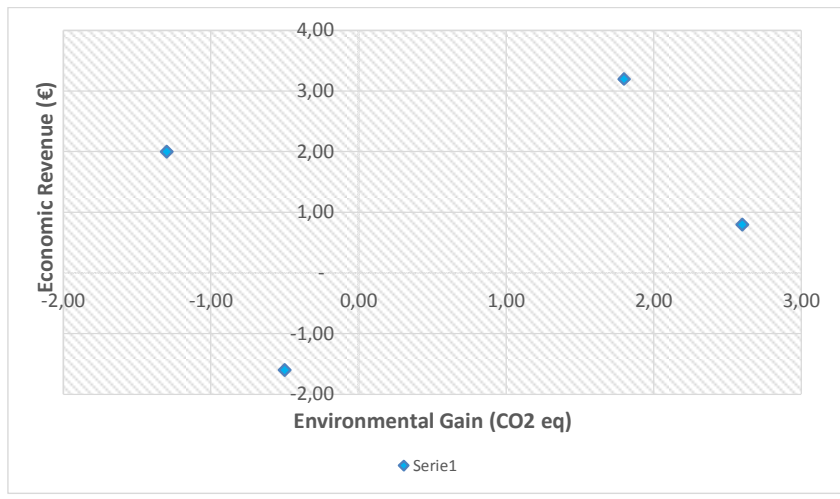

Fig. 1. Example of Eco-efficiency diagram 


\section{Literature Review}

The aim of this research is to evaluate the environmental impacts of end of life alternatives. The innovative approach developed in many studies during the last years, is the integration of economic dimension to the environmental one. The meaning of Sustainability includes the three dimensions: environmental, social and economic. The social sustainability has been excluded because is a qualitative dimension, and it does not have a bearing into the remanufacturing scenario. Might be interested, in the future, analyzing this aspect in waste management strategy. For the environmental evaluation, the methodology utilized is the Life Cycle Assessment, in a streamlined form. Life Cycle Assessment (LCA) is a structured, comprehensive and internationally standardized method. It quantifies all relevant emissions and resources consumed and the related environmental and health impacts and resource depletion issues that are associated with the entire life cycle of any products or services [6]. It has been implemented a simplified approach to include streamlining into the whole LCA framework. The methodology is compliant with the Society of Environmental Toxicology and Chemistry (SETAC) guidelines that, on July 1999 [7], established a list of streamlined part of a full LCA. Their investigation starts identifying a level of efforts required for each study, with two different approaches. In the first case, they introduce streamlining within the existing LCA framework, and in the second alternative streamlining approaches based on life cycle concepts. The purpose of these guidelines is to:

- redefine streamlining as an inherent part of any LCA approach;

- describe various ways that streamlining LCA has been attempted and investigated and the possible implications in different decision making contexts.

A small and simple Life Cycle Inventory has been developed, embracing the potential impacts for the inputs and the processes included into the analysis; Manmek S. and Kara S. [8] have chosen a similar approach. They presented a Simplified Life Cycle Assessment (SLCA) methodology to assess the environmental impacts, which are incurred during the life cycle stages of a product. The life cycle stages included into the work are materials, production processes, usage, transportation and end of life stages. The LCI has been applied with the case study of photocopier machine, and they have verified with a full LCA.

About the costs evaluation, the literature review shows the many differences between system boundaries and user goal. Richard Wood and Edgar G. Hertwich introduce the LCC as possible indicator in economic evaluation [9]. They have related the potential contradictions in system boundary to an environmental LCA. Further, it has an inherent contradiction between user goals (minimization of cost) and social goals (maximization of value adding), and has no clear application in a consequential setting.

In the context of PREMANUS project, a literature review about product remanufacturing research has been done. It has been investigated potentials interesting studies about environmental benefits of remanufacturing, to compare the methodology used in this research and the one used by others authors. In details, some studies about environmental evaluation have been analyzed; Some authors introduced a comparison between different alternatives of dismantling (e.g. recycling, reuse) and new products. 
In particular, it has been analyzed the study of Amaya J. et al. about the remanufacturing of truck injector [10]. The study shows how to established environmental assessments for remanufactured products life cycles and how to compare them to environmental assessments for new products life cycles.

This work tried to include the consideration of multiple cycles of remanufactured and reused products, to evaluate the comparison within new products. A similar approach has been used by Sutherland J. et al. that has been analyzed a comparison of manufacturing and remanufacturing energy intensities with application to diesel engine production [11]. They developed a procedure to standardize the benefits of remanufacturing. Their research determines the energy intensity and benefits of remanufacturing as compared to new manufacturing.In extensive literature research carried out on the broader remanufacturing field, only few papers have been found with a focus on LCA and remanufacturing of automotive engines comparing different end of life strategies. In none of those papers a specific link between environmental and economic implications was described. At the end, the innovation of this work is to exploit the results and the methodology in a software platform, using the life cycle data specific for a physical product. In this way, the results might be more accurate.

\section{Research Application}

The research defines the total benefit of end of life alternatives in term of environmental gain and economic profit. Within the PREMANUS project three industrial cases have been analyzed: the automotive engine and wind turbine gearbox remanufacturing strategy, and WEEE (Waste of Electric and Electronic Equipment) management. At this stage, the automotive engine case study has been fully implemented. As described in the Introduction the results will be expressed in a bi-dimensional graph to discover the best solution in terms of Environmental gain and economic profits.

\subsection{Methodology}

The methodology is different considering the environmental measurement and economic aspect.

About environmental dimension, the Life Cycle Assessment methodology has been applied in a streamlined form [7]. As mentioned in ISO 14044 the Life Cycle Assessment has been divided in 4 phases [12]:

1. Goal and Scope definition;

2. Life Cycle Inventory;

3. Life Cycle Impact Assessment;

4. Life Cycle Interpretation.

During the goal and scope definition the functional unit and system boundaries has defined. The research outlines the environmental implication about one engine sent to remanufacturing plant. 
The Fig. 2 shows the system boundaries analyzed during the evaluation. The section investigated in this research is the product End of Life, and in particular, the remanufacturing process and the material recovery. In detail, a complex product can be undergone the remanufacturing process or reused as such; in addition, the components can be sent to material recovery, in some case only one of this option is acceptable, and the practitioner can follow only one direction. Each of those alternatives makes benefits (except the dispose). The phases not included into the analysis are in grey, and the area focus on the research is in bold.

As it can see in Fig. 2 remanufacturing and reuse allow to avoid the impacts related to "beginning of life", like the extraction of raw materials and manufacturing phase. In the reduction of environmental impacts point of view, this situation is very important, because one of the most impacts is caused by the engine production and in particular by the raw materials extraction and procurement. An important difference between reused products and remanufactured ones is the life expectancy. As introduced before, the remanufacturing process bring a used or non-functional good to a "like new" functional one. In this case, a core may have a new complete residual life (around 20 years, or a certain mileage). Instead, a used engine, put back on the market, has a lower life expectancy depending on its previous life (e.g. mileage).

The material recovery allows to save raw materials, and in this way to reduce the impacts caused by extraction.

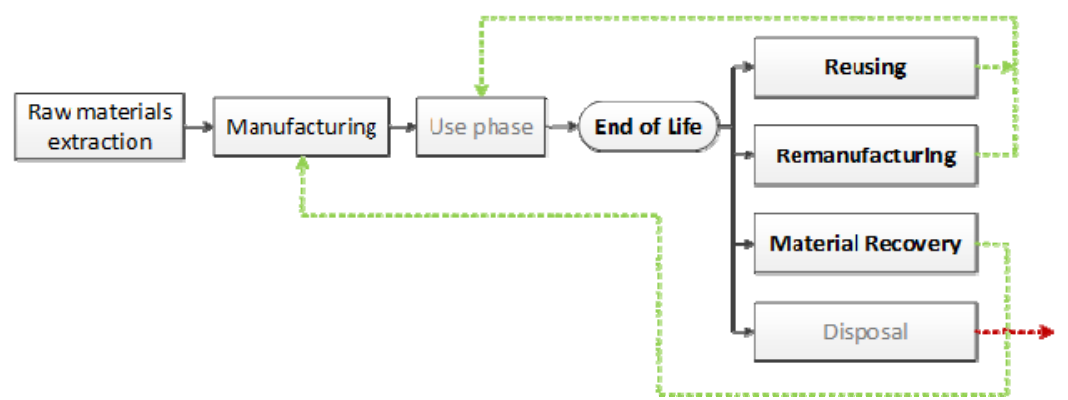

Fig. 2. Product life cycle flow

\subsection{Results}

Fiat operates a remanufacturing plant, which manages all types of FIAT Group engines every year. As analyzed during the case study, around 45\% are light engine, the type under discussion. Some simplifications, particularly in terms of engine components, have been considered in the research. In specific, only the major following components have been considered: cylinder block, cylinder head, pistons, connecting rods (conrods), crankshaft, flywheel, camshaft, turbo.

A core, after disassembly and washing process, is inspected and each component undergo a specific treatment. In some cases it may be necessary add new components, for example if the engine is incomplete, or if some components are useless. During the process the input considered for each step are electricity, compressed air, water consumption, oil consumption. 
In Fig. 3, energy consumption and other resources used for each option, expressed in percentage, and the distribution of energy consumption during each phase for the three options are displayed. In the graph on the left, some activities have the same energy consumption for the three options. At this stage of life cycle, the remanufactured engine cause higher energy consumption than the others options. In detail, only the remanufacturing process use resources in addition to electricity and water. The figure on the right shows the results in percentage to highlight the absorption of energy during the process.

Only for remanufacturing process accurate information has been used, about data to evaluate the processes avoided (e.g. manufacturing phase and raw material extraction) qualitative and statistical information have been extract from database Ecoinvent. Once listed the input interested to the remanufacturing process impact assessment can be evaluated. As explained in the previous section, the environmental performance indicator chosen for the analysis is equivalent $\mathrm{CO}_{2}$ emission, with the carbon footprint methodology [13], with Simapro 7.3. This indicator expresses the life cycle assessment limited to emissions that have an effect on climate change [14].

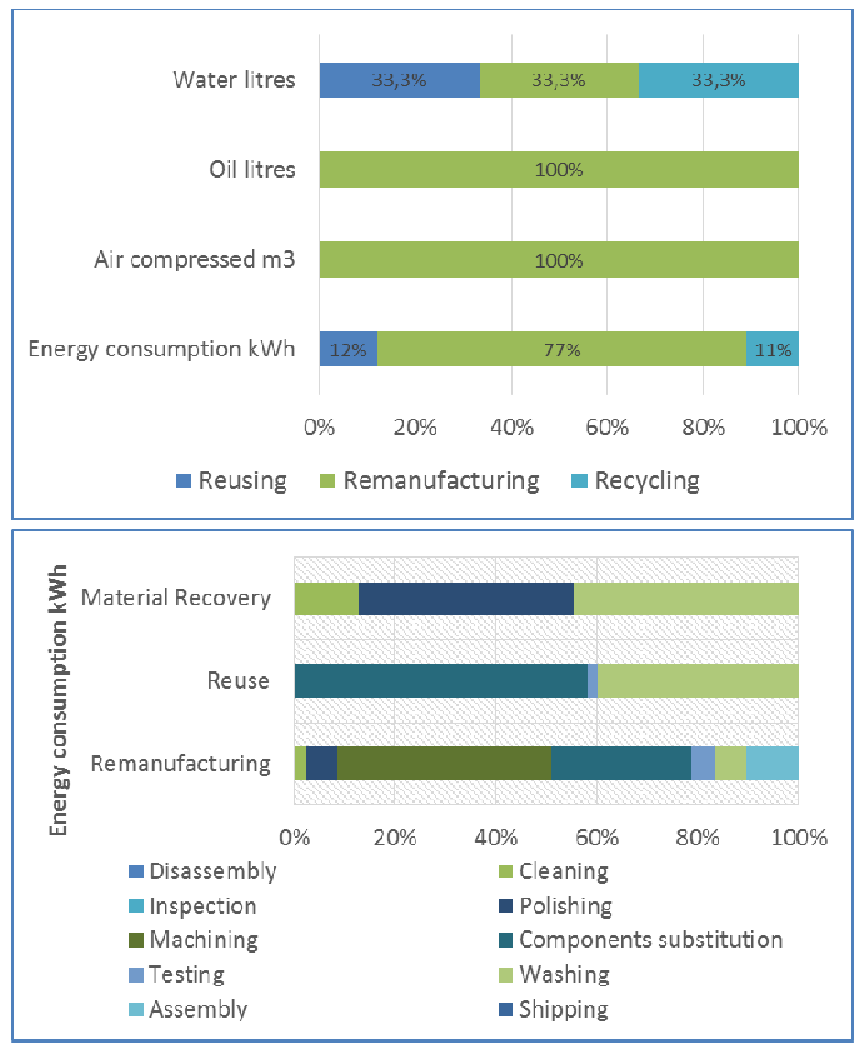

Fig. 3. Resources consumption reported in percentage for each activity and energy consumprtion for each options during the process phases 
Table 1 shows the results of analysis displayed as kilograms of equivalent $\mathrm{CO}_{2}$ emissions (Carbon footprint) and Euros $(€)$. Results include the impacts of the entire process conducted into the remanufacturing plant. As can be seen from the results, the remanufacturing causes more impacts during the process; the main reason is the resource consumption during the process. From life-cycle perspective, anyway remanufacturing leads to more environmental benefits compared to the other end-of-life alternatives. Indeed, the recycling processes have an important impact that reduce the benefits linked to avoided impacts about raw materials extraction. The difference between reuse and remanufacturing is mainly linked to the avoided manufacturing phase of new product. For reused goods, those benefits are anyway lower than remanufactured ones. From the economic perspective, materials recovery scenario revenues generated selling raw materials have been calculated. The final value shows that remanufacturing is the best solution, and a reused engine has more benefits compared to material recovery scenario.

Table 1. Impact assessment of three end of life options expressed in kilograms of equivalent $\mathrm{CO}_{2}$ emission

\begin{tabular}{|c|c|c|c|}
\hline Results & Reuse & Remanufacturing & $\begin{array}{l}\text { Material } \\
\text { recovery }\end{array}$ \\
\hline $\mathrm{kg} \mathrm{CO} \mathrm{O}_{2}$ eq. treatment process & 561 & 10.920 & 502 \\
\hline $\mathrm{kg} \mathrm{CO}_{2}$ eq. for recycling process & & & 337.154 \\
\hline $\begin{array}{l}\mathrm{kg} \mathrm{CO} \mathrm{C}_{2} \text { eq. avoided manufacturing } \\
\text { [10] }\end{array}$ & 28.978 & 72.446 & \\
\hline 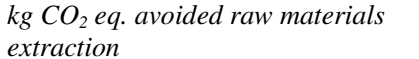 & 640.719 & 640.719 & 640.410 \\
\hline Benefits & -669.137 & -702.245 & -302.754 \\
\hline Revenue selling materials & & & $€ 108,46$ \\
\hline Steel & & & $€ 5,17$ \\
\hline Cast iron & & & $€ 34,85$ \\
\hline Aluminum & & & $€ 68,44$ \\
\hline$\underline{\text { Revenue selling engine }}$ & $€ 612,00$ & $€ 2.562,00$ & \\
\hline Operations costs & $€ 43,47$ & $€ 263,46$ & $€ 158,20$ \\
\hline Energy consumption & $€ 3,91$ & $€ 24,85$ & $€ 3,50$ \\
\hline Workforce costs & $€ 39,56$ & $€ 238,60$ & $€ 154,71$ \\
\hline Total revenues & $€ \mathbf{5 6 8 , 5 3}$ & $€ \mathbf{2 . 2 9 8 , 5 4}$ & $-€ \mathbf{4 9 , 7 5}$ \\
\hline
\end{tabular}

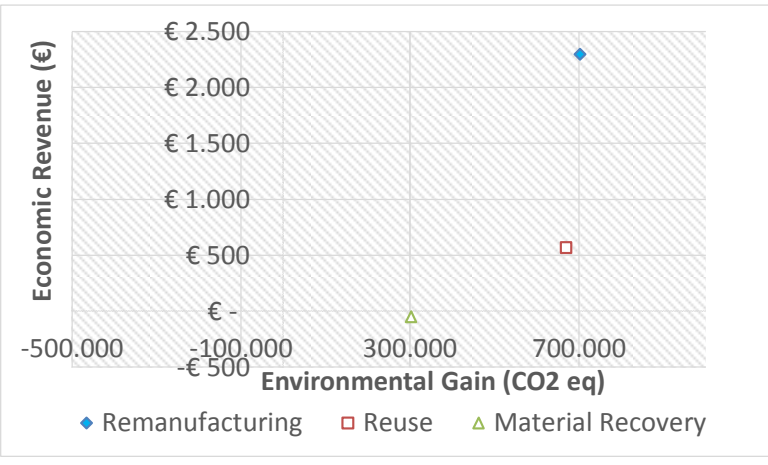

Fig. 4. Eco-efficiency diagram 
As described in the previous sections results are shown in a bi-dimensional graph (Fig. 4); in this way, it is possible see the difference of each option in term of environmental impacts and costs. This visualization allows decision makers to combine the two dimensions (environmental and economic) setting their own priorities.

Results may be different for different products. Indeed, this model will be used in a business decision support system to evaluate the three options into the remanufacturing plant of FIAT Group. As described in the previous sections the algorithm works with defined input, which will change with the life cycle data of the engine. Each core and its components will follows these three paths and the results will change on the graph.

Acknowledgment. Thanks to CRF (Centro Ricerche Fiat), which has supplied the data about remanufacturing process. The research leading to these results has received funding from the European Community's Seventh Framework Programme (FP7/20072013) under grant agreement $n^{\circ} 285541$.

\section{References}

1. EUROSTAT and European Environment Agency statistics (2013),

http://epp.eurostat.ec.europa.eu/statistics_explained/

index.php/Waste_statistics

2. Directive 2008/98/EC European Commission, of the European Parliament and of the Council, on Waste and Repealing Certain Directives (2008)

3. European Commission, "Being wise with waste: the EU's approach to waste management", Luxembourg, Publications Office of the European Commission (2010)

4. The European Parliament, the council: "Directive of the European Parliament and of the Council on Waste from Electrical and Electronic Equipment (WEEE)". Brussels (2002)

5. Walsh, B.: Remanufacturing in Europe - the Business Case, Sustainable Industry Forum, Brussels (2013)

6. European Commission, Istitute for Environment and Sustainability, "ILCD Handbook. Analysis of Exixting Environmnetal Impact Assessment Methodology for Use in Life Cycle Assessment", 1st edn. (2010)

7. Weitz, K., Sharma, A., Vigon, B., Price, E., Norris, G., Eagan, P., Owens, W., Veroutis, A.: Streamlined Life-Cycle Assessment: a Final Report from the SETAC North America, Streamlined LCA Workgroup, SETAC (1999)

8. Manmek, S., Kara, S.: Application of the Simplified Life Cycle Inventory for a Product Life Cycle. In: Proceedings of the 7th Australian Life Cycle Assessment Conference, Melbourne, Australia, November 22-24 (2009)

9. Wood, R., Hertwich, E.G.: Economic modelling and indicators in life cycle sustainability assessment. The International Journal of Life Cycle Assessment 18 (2013)

10. Amaya, J., Zwolinski, P., Brissaud, D.: Environmental Benefits of Remanufacturing: the Case Study of the Truck Injector., G-SCOP Laboratory, Grenoble, France (2010)

11. Sutherland, J.W., Adler, D.P., Haapla, K.R., Kumar, V.: A Comparison of Manufacturing and Remanufacturing Energy Intensities with Application to Diesel Engine Production. CIRP Annals, Manufacturing Technology 57, 5-8 (2008)

12. ISO 14044, "Environmental Management - Life cycle assessment - Requirements and guidelines" (2006)

13. ISO 14067, "Greenhouse gases - Carbon footprint of Products - Requirements and Guidelines for Quantification and Communication" (2013)

14. European Commission, "Carbon Footprint - What it is and How to Measure it", European Platform of Life Cycle Assessment (2007) 